\title{
Unravelling the Threads of War and Conflict Introduction
}

\author{
Authors: Lydia C. Cole $\vee$, University of York, UK, Laura Mills $\checkmark$, University of St Andrews, \\ UK
}

Lydia Cole is an Associate Lecturer at the University of York. Her most recent research has engaged with arts and global politics, with a focus on grassroots arts for change in Bosnia and Herzegovina. In 2019, she was Associate Lecturer at the University of St Andrews, where she commissioned and co-curated Threads, war and conflict, as well as coordinated and led its associated events programme. The exhibition featured arpilleras and textile banners from the Conflict Textiles collection.

Laura Mills is a Lecturer in International Relations at the University of St Andrews. She was a member of the Threads, war and conflict curatorial team, including staff co-lead of the Master's student workshops resulting in a collective textile for the Conflict Textiles collection. Her research explores how everyday life and culture are co-constitutive of global politics through examinations of cultural diplomacy, war, militarism, security, aesthetics and creative methods. Her first monograph, Post-9/11 US cultural diplomacy: the impossibility of cosmopolitanism, is forthcoming with Routledge New International Relations Series.

\begin{abstract}
This article introduces the Special Issue 'Unravelling the threads of war and conflict'. We offer a careful curation of three threads of conversation generated from the exhibition Threads, war and conflict and its associated programme: 'Reflections on curating, exhibiting and making'; 'Layers of war and conflict: sightings and soundings'; and 'Conversations and collaborations, stories and solidarities'. Beginning from the context of the exhibition, the threads of conversation unravel (across) a variety of intricate sites and intimate experiences of war and conflict.
\end{abstract}

Keywords: Textiles; War; Conflict; Exhibitions; Making; Art

In April 2019, Threads, war and conflict, an exhibition of textiles (arpilleras and banners) from the Conflict Textiles collection, took place at the Byre Theatre, St Andrews. Organised by a small team of researchers within the University of St Andrews' School of International Relations, the exhibition presented textile stories of violence and its resistance. These textile stories touched on key themes addressed within the School of International Relations, including testimonies of disappearance, gendered resistance to militarised violence, explorations of displacement and migration, and reflections on the ethics of drone warfare. The exhibition 
was accompanied by a programme of events including a library exhibition, public lectures, textile workshops and academic conferences, and was integrated into teaching and research in the School of International Relations in the academic year 2018/19.

This Special Issue offers threads of conversation and reflection generated through and emerging from Threads, war and conflict. These threads extend beyond the exhibition, unravelling (across) a variety of intricate sites and intimate experiences of war and conflict. The Issue, therefore, draws together several creative projects. Some emerge through the process of collaborating, curating and connecting through Threads, war and conflict, while others arise beyond this context, responding to and building upon the themes of the Special Issue. All grapple with aspects of violence and its resistance, which are featured within the exhibition and its spaces of discussion. In the Issue, we thread together a series of creative interventions, including dialogue, critical reflection, poetry, visual analysis, collage and performance. These interventions are organised around three central threads of conversation and reflection. The first reflects on processes of curating, exhibiting and making in Threads, war and conflict. Moving beyond the site of the exhibition, the second thread explores the layers of war and conflict through the engagement of sight and sound. Reflecting on conversations and collaborations forged within textile projects like and beyond Threads, war and conflict, the third thread contemplates the stories and solidarities which emerge through textiles and their making.

Throughout, we have aspired to a "careful curation" of each intervention and the threads they comprise. With regard to conflict textiles, Andrä et al. (2020, p. 343) reflect that careful curating is a mode of threading together different narratives, while giving space for their 'multiple, overlapping and sometimes incongruent meanings' to flourish. In this Issue, authors take on the task of unravelling the threads of war and conflict in multiple directions. When read together, the pieces form 'relations and become weavings that transform us' (Tickner and Querejazu, 2021, p. 15); that is, through careful curating, the threads of these creative interventions connect, both in terms of their words and their worlds.

\section{Thread 1. Reflections on curating, exhibiting and making}

The first set of creative interventions responds to the exhibition and its associated programme, reflecting on its organising, curating and processes of making. The dialogue 'International Relations and/as thread-work' co-authored by Selena Jamallulail, Roberta Bacic, Lydia C. Cole and Laura Mills explores the material artefacts of the exhibition. Engaging the language of thread-work, the dialogue examines the interactive, tactile and emotional aspects of the exhibition, including its featured textiles and processes of textile-making in the exhibition programme. Their creative unravelling of the exhibition shows how curating conflict textiles engenders alternative ways of knowing and doing IR. The latter articles in this section engage with processes of textile-making within the collective textile workshops 'Responding to Threads, war and conflict: letters to arpilleristas'. In the workshops, participants were asked 
to respond to the theme of home embodied within the textiles in the exhibition. Offering 'Reflections on Threads, war and conflict', Rachel Beattie, Frankie Copp and Schoutje Schouten explore voice in arpilleras and IR more widely and draw this discussion of voice through to their own experiences of making. Showing that arpilleras offered women a way of expressing opposition to violence under the dictatorship of Augusto Pinochet, they suggest that understandings of voice must extend well 'beyond the spoken word'. In 'Stitch after stitch', Daniela Lara Espinoza, a Chilean contemporary textile artist and workshop participant, reflects on making an arpillera on 'home' and climate emergency. Moving across scales of (dis)connection - in the workshop, her professional practice, communities in Chile and the planet - Espinoza situates stitching as a form of 'intimate' activism, which entails telling stories and the act of letting go as politics.

\section{Thread 2. Layers of war and conflict: sightings and soundings}

The second set of creative interventions reflects themes within the exhibition, examining layers of war and conflict through visuality, sound and/or making. Moving beyond the exhibition and its associated programme, this section draws in multiple creative responses to the experience and remembering of war and conflict. Eileen Harrisson moves between narrative, reflection and poetry in 'Documenting the Troubles through stitch, sound and word'. The piece threads together various (remembered) experiences of conflict, from the Troubles in Northern Ireland to images of war in Aleppo, Syria. Weaving together stitch, sound and poetry, Harrisson highlights how these forms of creativity can document the physical, emotional and psychological impacts of conflict. Giovanna Di Mauro's reflective review centres on the medium of photography to explore war and conflict as multiple sites and sights. Focusing on Ian Alderman's Recovering the past, Di Mauro notes that these photographs stitch multiple voices together. Collaging present-day conflict landscapes with black-and-white images of soldiers who served and died in these battlefields, Di Mauro threads together layers of personal, critical and audience responses to Alderman's photographs.

Jenny Edkins also responds to a photograph, in this case through a poem entitled 'A migrant and her two-year-old daughter in Tijuana'. The poem unravels layers of conflict through its exploration of affective (dis)connection in Ilana Panich-Linsman's photo of the pair. Starting from a feeling of connection with Arlen Cruz (the migrant depicted), Edkins notes a familiarity with the way she holds the child. Moving through disconnection, and reflecting on the way that the photo renders the migrant and child as 'spectacle', Edkins concludes with a hopeful, yet ambiguous future in which the 'young women hold[s] the world in her arms'. Exploring the camouflage craftivist movement 'The Spiders' in Ukraine in the wake of Russian occupation, Olga Boichok untangles layers of war and conflict in/across multiple sights, sites and scales: first, in navigations of how through this 'camouflage aesthetics', militarisation, craftivism and the in/visibility of resistance at scale overlap, intertwine and disrupt one another; second, in the camouflage itself, where literally the layers of cloth form a plane of representation that cross-cuts fields of vision to render invisible and enact 
resistance hidden in plain sight; third, in three ontological cuts across which camouflage unsettles hegemonic understandings of militarising aesthetic by interrogating the relationship between visibility and survival on a macroscopic scale to remediate the spatial and temporal multiplicities and discontinuities in which war is wrought, thought and fought as decolonial resistance; and, finally, in Boichok's own creative practice of algorithmic collage which, via the cutting and layering of fragments, turns these 'ontological cuts' into seams to illustrate their entanglement and enact 'Camouflage: an aesthetic of resistance'.

\section{Thread 3. Conversations and collaborations, stories and solidarities}

The final set of creative interventions extends beyond the exhibition to explore how textiles and textile-making lead to multiple collaborations, stories and solidarities that stretch across the globe. Both interventions take the form of conversations that are accompanied by photographs of textiles and textile-making across a variety of spatial and temporal sites, whether the virtual, verbal or textual sites of their conversation, the locations of Mexico and Colombia (and beyond), or the textiles as sites of 'doing memory' in the past, present and into the future. Having forged a connection through collective embroidery and textile responses to recent violence in Mexico, specifically Bordando por la paz y la memoria, Danielle House, Cordelia Rizzo and Rosa Borrás reflect on a Whatsapp exchange on their participation in personal and collective embroidery projects to social injustices now in their different corners of the world and time zones. Building on Audre Lorde's call to 'be in contact', they demonstrate how through "the kitchen table" of social media, these digital conversations and textile practices foster collaborative communication, cultivate solidarity and develop political capacities across space and time. Illustrating the potently affective relationship between embroidery and conversation as key to mobilising political projects, they critically explore and question - without providing easy answers - the politics and implications of their actions and what it means for these intimate projects to be visibilised in the world and the effects engendered as they move further, spatially or symbolically, from the people and communities they represent. Drawing on their respective research (and) experiences in the context of the armed conflict and fragile peace process in Colombia, Berit Bliesemann de Guevara and Roxani Krystalli's engaging conversation explores how textiles can open up space for different kinds of storytelling about violence, memory and transformation in the aftermath of armed conflict. They trace the multiplicities and complexities of how textiles are narratives and forms of narration about violence and peace, as well as sites of memorymaking for those who contribute to their creation. Doing so reveals how textiles are also 'a window to thinking and feeling otherwise about labels and experiences of violence'. For in regarding textile-making as 'doing memory' can emerge the highly affective, embodied and contested politics of storytelling through textiles and textiles as storytelling. 
It is in gathering these threads together that the Special Issue can also enable their unravelling in ways which reveal their rich and varied insights on the complexities of war and conflict. These creative interventions enable: an exploration of the diverse ways in which conflict textiles speak international politics; reflection on how politically engaged stitch (and creative practice) can be used as a form of resistance; an evaluation of how textiles and stitching can be mobilised as sites of/for pedagogy; and an interrogation of stitch and textile as a method with which to engage in practice-based research on war and conflict. Just like the visual artefacts which inspire these creative interventions, the pieces and their careful curation enact 'a visible entanglement of knowledges' that is (self-)critically attuned to the possibilities of their ambivalence (Rogers, 2020). These threads entangle to offer multiple ways of knowing that do not foreclose one another or propose fixed conclusions, but leave openings through their ongoing and unravelling threads. Following these threads in our modes of doing IR encourages us to reflect on and question our entanglements, and indeed, solidarities, which emerge through engagement with textiles and their making.

Our collective focus on textiles and textile-making aims to render visible ways of knowing and questioning that, far from seeking determinacy or fixity, are grounded in and foster intimacy, care, consideration and the unbounded politics of possibility these enact. Embracing textiles in this way is to rethink and imagine IR as a site of 'being-feeling-knowing-doing' (Tickner and Querejazu, 2021, p. 394). The creative interventions in this Issue take us elsewhere, and provide nuances on the emotional, everyday and embodied experiences and encounters of/with war and conflict. In their collectivity and curation, it has been our aim for these interventions and the threads they comprise, to become emotional, everyday and embodied experiences and encounters of and with war and conflict themselves.

\section{Acknowledgements}

The Threads, war and conflict exhibition and associated events programme was coordinated by Dr Lydia C. Cole, with Dr Faye Donnelly, Dr Laura Mills and Dr Natasha Saunders in collaboration with Conflict Textiles curator Roberta Bacic and assistant curator Breege Doherty. The exhibition was hosted by the School of International Relations in cooperation with The Byre Theatre, while the events programme was supported by Contemporary Voices: The St Andrews Journal of International Relations, the Handa Centre for the Study of Terrorism and Political Violence (CSTPV), International Security Studies (ISS), Peace and Conflict Studies (PCS), International Political Theory (IPT), the Centre for Global Constitutionalism (CGC) and the Teaching Enhancement Fund, University of St Andrews. 


\section{References}

Andrä, C., Bliesemann de Guevara, B., Cole, L. and House, D. (2020) 'Knowing through needlework: curating the difficult knowledge of conflict textiles', Critical Military Studies, 6 (3-4), pp. 341-359.

Rogers, C. (2020) 'Almost always clouds: stitching a map of belonging', in Iosefo, F., Holman Jones, S. and Harris, A. (eds) Wayfinding and critical autoethnography. London: Routledge, pp. 151-167.

Tickner, A.B. and Querejazu, A. (2021) 'Weaving worlds: cosmopraxis as relational sensibility', International Studies Review, 23 (2), pp. 391-408. 